\title{
Direito Internacional Privado, unificação do Direito e Comunidade Econômica Européia.
}

\author{
Rudolf Moser \\ Protessor de Direito Internacional Privado \\ da Universidade de Ciências Econômicas e \\ Sociais de S. Gallen (Suissa). Professor As- \\ sistente da Faculdade de Ciências Juridicas \\ do Rio de Janeiro.
}

O Direito Internacional Privado trata de fatos ou relações de direito privado na medida em que êstes tiverem conexão com mais de uma ordem jurídica. Ésses fatos ou relações internacionais devem sujeitar-se a um dos direitos em questão, ficando em geral excluída, por razões teóricas e práticas, a aplicação simultânea de dois ou mais direitos. $O$ D.I.P. cumpre a sua tarefa por meio das assim chamadas "regras de colisão ou conflito", i.e. de normas que determinam a lei aplicável na base de um certo critério. Este critério, denominado "circunstância de conexão", é um elemento da relação, considerado determinante por efetuar a aplicação da lei adequada ${ }^{1}$. Assim é adotada atualmente, para os contratos internacionais de compra e venda, a lei do país onde o vendedor fôr domiciliado ou residente, por ser êle quem faz a prestação característica (o fornecimento da mercadoria) e quem sustenta, em primeiro lugar, o onus do contrato; vide o art. 3 da Convenção de Haia sôbre a lei aplicável a contratos de caráter internacional de compra e venda de móveis, de 15 de junho de 1955 .

1. Determinar a ligação idônea, certa, justa, entre relação e norma de direito significa apreciar, julgar, e isto é que faz da regra de conflito uma norma de direito, da técnica de aplicar leis estrangeiras à ciência do D.I.P. 
Ao D.I.P. compete função internacional; visto a "pluralidade legislativa espacial" 2 , trata-se cada vez de determinar e aplicar ${ }^{3}$ uma das diversas ordens jurídicas coexistentes. Porém, à função internacional não corresponde uma origem internacional das normas de conflito: a sua fonte é nacional, estadual. Só existe Direito Internacional Privado francês, português, brasileiro, etc., e a dita tarefa pode ser cumprida sòmente do ponto de vista de um pais, de uma ordem jurídica, salvo normas de conflito criadas por tratados internacionais, tais como as Convenções de Haia sôbre o direito da família, de 1902; de Havana sôbre o D.I.P. em geral (Código Bustamante de 1928), de Genebra sôbre cambial e cheque, de 1930/31; de Haia sôbre a compra e venda, já citada. Nestes casos existe "Direito de Conflito" convencional ou comum, o qual, todavia, vigora nos Estados contratantes como direito estadual, nacional, apesar da sua função e fonte internacionais.

Um fato internacional pode ser regulado diretamente, sem intermédio de normas de conflito e sem aplicação de direito estrangeiro; isto no plano nacional bem como no plano internacional. No plano nacional intervêm as "normas materiais com elementos estrangeiros ou internacionais", de uso geral para a condição dos estrangeiros, aplicadas também no direito das companhias e sociedades comerciais $^{4}$ e noutras partes do direito comercial e civil. No plano internacional existem tratados que regulam direta-

2. Haroldo Valladão, Direito Internacional Privado, Direito Uniforme e Direito Comparado, in Revista "Ciências Jurídicas" do Instituto Clóvis Bevilaqua, Fortaleza 1961, p. 119 s., 148.

3. Ou "incorporar", vide WERNER NIGDERER, Einfuehrung in die allgemeinen Lehren des internationalen Privatrechts (Introdução à teoria do D.I.P.), Zurique 1956, p. 137 nota 10, — ou "imitar", segundo as teses de Amílcar de CASTro, D.I.P., Rio de Janeiro 1956, vol. I p. 308.

4. P. ex., o art. 711 do Código suiço das Obrigações exige que - conselho administrador da sociedade anônima se componha na sua maioria de pessoas de nacionalidade e domicílio suiços, podendo o govêrno dispensar desta exigência no caso de "holdings" estrangeiras. 
mente relações privadas internacionais, sem intercalar normas de conflito. Êstes casos são, porém, raros, e a sua manipulação é difícil - vide, p. ex., as convenções sôbre a propriedade imaterial e os novos tratados bilaterais estipulando indenização para nacionalizações de bens estrangeiros. Tais normas únicas, materiais, sejam elas nacionais ou internacionais, não fazem parte do Direito de Conflito, mas sim do D.I.P. num sentido mais amplo ${ }^{5}$.

O Direito de Conflito reconhece-se como medida de emergência $^{6}$, como método defeituoso para dominar as divergências que separam as ordens jurídicas, para contemporanizar o melhor possível a "contrariedade dos preceitos jurídicos" (VAlladão). As normas de conflito nacionais já não garantem a "harmonia das sentenças" por serem (potencialmente) diferentes de Estado a Estado; por isso, a sua intervenção - em vez de aproximar as legislações umas às outras - junta aos conflitos causados pela diversidade das normas materiais outros conflitos mais, a saber os causados pela diversidade das próprias normas de conflito. A sua existência se justifica ùnicamente pelo desejo de saber, do ponto de vista de um só direito, qual das diferentes ordens jurídicas seja aplicável ao fato (ou à relação) internacional. Este desejo imperativo é portanto a "ratio legis" da norma de conflito.

As normas de conflito convencionais, criadas por tratados, são capazes de produzir aquela harmonia das sentenças, pois o caso vai ser julgado segundo a mesma lei (indicada pela norma de conflito), independentemente do lugar do julgamento. Todavia, os elementos das normas de conflito arriscam-se a ser interpretados diferentemente de fôro a fôro ${ }^{7}$, o que faz com que a sua aplicação uniforme

5. As relações dêste tipo de direito uniforme com o D.I.P. são aprofundadamente discutidas na citada obra de H. Valladão, p. $124 \mathrm{~s}$.

6. ADOLF F. ScHNITZER, Handbuch des IPR (Manual do D.I.P.), Basilea 1957, 4. a ed. vol. I, p. 57.

7. Resolveu-se, por isto, a qualificá-los no tratado mesmo, ou a indicar nele a lei competente para a qualificação, vide p. ex. a Con- 
não esteja posta a salvo e sempre há o perigo de surgirem divergências na determinação do direito aplicável conforme o lugar da sua efetuação.

O problema da interpretação ou qualificação e outras dificuldades específicas, bem como o constatar que a intervenção de normas de conflito complica a apreciação dos fatos internacionais, levam a que a uniformização das normas de conflito ("Kollisionsrechtsvereinheitlichung") sòmente seja aspirada quando a unificação das normas materiais ("Sachrechtsvereinheitlichung") não fôr possível". Este meio direto para alcançar o Direito Uniforme, o método da "uniform legislation", também é imperfeito, sendo que a igualdade das normas pode se perder por atos ulteriores dos Estados contratantes, perigo que subsiste enquanto a jurisdição sôbre as matérias compete a êles. Além disso,

venção de Haia sôbre os conflitos entre a "lex patriae" e a "lex domicilii" (chamada Convenção do "renvoi", da remissão), de 15-6-1955, art. 5; Convenção européia sôbre conflitos do domicílio, celebrada em Paris em 13-12-1955, Protocolo ao art. 30.

8. Resulta porém dos estudos de Bernhard C. Aubin, Europaeisches Einheitsrecht oder intereuropaeische Rechtsharmonie? (Direito uniforme europeu ou harmonia de direito intereuropeu?), em KoNRAD ZWEIGERT, Europaeische Zusammenarbeit im Rechtswesen (Colaboração européia no campo de direito), Tuebingen 1955 , p. 45 s., 54 nota 12 , que existem fatos internacionais (especialmente no direito da família e das sucessões) com "centro de gravidade" na esfera nacional, de maneira que para êles só o método da unificação das normas de conflito dá resultados adequados. A unificação das normas materiais deve respeitar as diversidades de ordem ética-jurídica, o "legítimo acento indígena" das instituições nacionais e limitar-se às matérias "nacionalmente indiferentes", idôneas a unificar. Neste sentido, VALLADÃo, op. cit. p. 131, sublinha que o direito uniforme pode compreender apenas certos assuntos. ERnesto CoRdetro AlvaREZ e ZWETGERT, Die Rechtsvergleichung im Dienste der europaeischen Rechtsvereinheitlichung (0 direito comparado servindo a unificação do direito europeu), Rabels Zeitschrift fuer auslaendisches und internationales Privatrecht, Tuebingen/Berlim 1951 , vol. 16 , p. $387 \mathrm{~s} ., 389$, já tinham verificado que são alcançáveis à unificação das normas materiais em primeiro lugar os fatos ou matérias com preponderância do conteúdo econômico. Quanto ao Mercado Comum Europeu isto procede. 
salvo a identidade das normas materiais uniformes nos Estados contratantes, podem surgir divergências de interpretação, tanto no campo de unificação direta como naquele de unificação indireta, por meio de normas de conflito. As conseqüências aquí, porém, vão ser menos graves, baseando-se as sentenças, independentemente de fôro, no mesmo texto (da norma material unificada) ${ }^{9}$. As normas de conflito são supérfluas quando as normas materiais coincidem.

A uniformização do direito - por via direta ou indireta - tem o maior sucesso onde é o mais urgente e onde intervem o menos possível em tradições jurídicas, a saber no direito da propriedade imaterial, da viação, da letra de câmbio e do cheque, da compra e venda e do comércio em geral. Os resultados obtidos são devidos, em grande escala, aos esforços dos institutos científicos e das organizações de direito internacional, a saber ao "Institut de Droit International", à "International Law Association", ao "Instituto Internazionale del Diritto Privato", à "Conferência de D.I.P.", de Haia, e a outros grêmios ${ }^{10}$.

De resto, a história do direito privado demonstra ${ }^{11}$ que a unificação ou uniformização das leis particulares realiza-se sòmente sob circunstâncias especiais de caráter espiritual, político ou econômico: foram frutos das idéias do direito natural e do Estado nacional as grandes codificações nos séculos xvIII e xIx - Allgemeines Preussisches Landrecht, Code civil français, Oesterreichisches Allgemeines Buergerliches Gesetzbuch, Codice civile italiano; os códigos civis alemão e suiço (Buergerliches Gesetzbuch,

9. Combate-se as divergências de interpretação em obrigar os Estados contratantes a fazerem relatórios sôbre a sua jurisdição na matéria, em instituir tribunais interestaduais, etc. .

10. Vide, sôbre os movimentos uniformizadores, VALLADão, op. cit. p. 131 s..

11. SCHNITZER, De la diversité et de l'unification du droit, Basiléa 1946, p. 43 s.; VAlladão p. 131. 
Zivilgesetzbuch) foram condicionados pela criação de um Estado federal; o Código de Comércio alemão (Handelsgesetzbuch), de 1861, resultou da União alfandegária alemã, o projeto franco-italiano de um Código das Obrigações, de 1927, e a colaboração dos Estados da Europa nórdica no campo de direito privado baseiam-se no fundamento comum do Code civil resp. da tradição do direito germânico. A cooperação dos Estados Benelux deu-se pela sua comunidade cultural de vizinhança.

São sobretudo razões extra-jurídicas que estimulam decisivamente a unificação do direito; sob a influência delas, sòmente, os protetores das ordens jurídicas se tornam dispostos a desviar-se das sagradas regras hereditárias do direito civil, a abandonar os "arquetipos jurídicos" (Zweigert) e a consentir a uniformização no plano interregional, internacional ou, ùltimamente, supra-nacional.

Quais as características da supranacionalidade em relação ao D.I.P. e à unificação do direito? Ultrapassando a esfera da simples internacionalidade - na qual a criação de normas de conflito, de normas materiais com elementos internacionais ou de normas materiais uniformes efetua-se por tratados estatais e no próprio texto dêles - o novo método para ensaiar a harmonia dos direitos ou das sentenças consiste em instituir, pelo tratado, uma autoridade superestatal, à qual fica conferida a tarefa de resolver o problema. A esta autoridade compete regular os fatos de natureza internacional privada, seja de modo indireto, mediante normas de conflito supranacionais, seja de modo direto, mediante normas materiais supranacionais, seja ordenada a uniformização das leỉs nacionais por via tradicional. Qualquer que seja o modo escolhido, a atividade legislativa da autoridade supra-nacional ordenadora juridica ("uebernationale Rechtsbefehlsstelle", SCHNITZER) é capaz de propulsionar enormemente a unificação do direito 
e de impedir, aliás, a decomposição posterior dêste estado de coisas, i.e. do Direito Uniforme estabelecido ${ }^{12}$.

A Comunidade Econômica Européia tem a finalidade de instalar na Europa uma entidade econômica (mais tarde política), abolindo as restrições alfandegárias e outras que impeçam a livre competição. o "Mercado Comum" é o primeiro objetivo da Convenção de Roma de 25 de março de 1957 , em vigor desde $1 .^{\circ}$ de janeiro de $1958^{13}$. Foram causas extrajurídicas, da economia européia que produziram esta formação que ainda não é confederação, mas sim, uma comunidade dos Estados contratantes (ou membros), formação esta que aspira, além de a outros alvos, à unificação de direito civil particular. $O$ impulso veio do lado econômico e não do jurídico. Enquanto era proposta por eminentes juristas alemães ${ }^{14}$, no após-guerra, a união européia de direito privado, o que se realizou é a Comunidade Européia Econômica.

Vamos brevemente examinar o teor do Tratado (ou Estatuto) de Roma para saber em que escala o Mercado Comum Europeu propõe e proporciona o Direito civil uniforme.

Segundo o artigo 3, letra $h$, a atividade da CEE compreende a adaptação (ou aproximação) das leis particula-

12. A criação institucional de normas supraestaduais não deve ser confundida com a tentativa dos "internacionalistas" de deduzir tais disposições do direito das gentes - concepção irreal de superdireito, vide Oscar TenóRIo, D.I.P., Rio de Janeiro 1962, 7. ${ }^{a}$ ed., vol. I, n. ${ }^{\circ} 260$, p. 185 .

13. Ver o art. 2 - Simultâneamente com a CEE foi fundada a Euratom, Comunidade Européia Atômica, enquanto a União Mineira, Comunidade Européia de Carvão e Aço, data do ano de 1951. Estas duas organizações têm mais o caráter de uniões administrativas, ao invés da CEE cujas finalidades são principalmente legislativas; ver WOHLFARTH, Europaeisches Recht, Von der Befugnis der Organe der EWG zur Rechtsetzung (Direito Europeu, Da competência legislativa dos órgãos da CEE), Jahrbuch fuer internacionales Recht, Goettingen 1960, vol. 9 , p. 12 s., 13.

14. A saber ZWEIGERT e AUBIN, ver as publicações citadas na nota 8 . 
res (dos Estados membros) na extensão que o fôr necessário para o devido funcionamento do Mercado Comum. Veja-se que um fator do comércio exterior serve de medida para a "adaptação ou aproximação"15 das leis, fator êste que é menos um fato do que um desejo. O primado da Economia sôbre o Direito não podia ser mais acentuado do que por esta subordinação: a adaptação das leis, a determinação e limitação das matérias a serem adaptadas, dependem das exigências e do bom funcionamento do Mercado Comum. Jamais a uniformização de normas de direito deve ter sido tão extremamente ligada a uma noção de avaliação ("Ermessensbegriff"), a um dado empírico, até mesmo a um postulado, como aquí, no Tratado de Roma.

Verificamos, por um lado, a falta de determinação em alto grau quanto às categorias a serem adaptadas: direito material e de conflito, direito público e privado, direito social, direito administrativo, e (caso seja preciso) inclusive direito constitucional; as prescrições sôbre alfândega, sôbre condição dos estrangeiros e impostos; direito das pessoas, dos contratos e obrigações, das companhias e sociedades comerciais, da concorrência e dos "trusts" - resumindo, em conjunto, o direito da economia no mais amplo senso; por outro lado, para a adaptação destas matérias, um critério que sòmente pode ser concretizado por meio de métodos científicos, sobretudo da estatística. O "devido funcionamento do Mercado Comum" é um ideal a ser diàriamente realizado, em condições flutuantes. É verdade que o Estatuto da CEE, na segunda parte (sôbre os fundamentos da Comunidade) e na terceira parte (sôbre a política da Comunidade), estipula detalhadamente o que deve ser feito para alcançar o alvo e quais são os meios à disposição. Porém, as conseqüências desta atividade puramente econômica sôbre as ordens jurídicas dos Estados membros são altamente incertas, e temos que constatar que o Mercado Comum Europeu prevê a unificação do

15. Sôbre estas noções vide adiante. 
direito em setores e numa extensão mais ou menos desconhecidos.

Tanto mais importante a tarefa dos órgãos da CEE, aos quais ficou concedida, "ipso facto", vasta liberdade de movimento, conforme a circunscrição sumária das leis a serem adaptadas ou aproximadas. A sua apreciação é pràticamente ilimitada ${ }^{16}$. Arbitrariedade poderá ser julgada pelo tribunal da Comunidade, por meio do assim denominado "contrôle das normas" (art. 17 do Estatuto), mas difìcilmente seria confirmada. Justifica-se, portanto, a opinião que, em relação à função dos órgãos da cEE no campo da adaptação do direito, as habituais garantias constitucionais fazem falta, ao menos até certo ponto. Devia ser instaurada jurisdição competente para revisar livremente esta atividade legislativa, como procede, conforme o art. 172, quanto aos "regulamentos", mas não quanto às "diretrizes".

Quais os órgãos incumbidos da adaptação ou aproximação das leis, e qual o respectivo procedimento? Dispõem sôbre a matéria os artigos 100 a 102.

0 art. 100 confere ao Conselho dos Ministros a competência de unânimemente decretar, por proposta da Comissão, diretrizes sôbre a adaptação das disposições legais e administrativas dos Estados membros, contanto que estas disposições se referiram imediatamente à instituição ou ao funcionamento do Mercado Comum ${ }^{17}$.

$O$ fato de ser exigida a unanimidade e de o Conselho se compôr de representantes dos governos (vide o art. 146), podia levar à conclusão de que seja necessário o consentimento de todos os Estados membros, i.e. que, por isso, estar-se-ia tratando de nada mais do que simples internacionalidade $^{18}$. Todavia, o funcionamento dos órgãos da

16. Wohlfarth, op. cit., p. 15.

17 Têm que ser ouvidos a Assembléia (o "Parlamento Europeu") e o Comité Econômico-Social, sendo os órgãos fiscalizadores e consultores.

18. Assim, quanto ao Conselho dos Ministros, JAEnicke, Der uebernationale Charakter der EWG ( $O$ caráter supranacional da CEE), Zeitschrift fuer auslaendisches oeffentliches Recht und Voelkerrecht, Koeln/Berlim 1958, vol. 19, p. 153 s., 171/72. 
Comunidade, segundo o seu Estatuto, difere tão fundamentalmente da conclusão de um tratado estadual, que está fora de dúvidas a supranacionalidade do procedimento unificador de direito privado na CEE ${ }^{19}$.

$\mathrm{O}$ art. 101 prevê consultas da Comissão com os Estados membros para adaptar ou harmonizar as leis e disposições concernentes às condições da competição. Pressuposto que a divergência das leis e disposições causasse deformação do Mercado Comum e que as consultas não remediassem, o Conselho, por proposta da Comissão, tomará as medidas adequadas. Desta vez, a capacidade de ação é maior; não só podem ser decretadas diretrizes, mas sim aplicados quaisquer outros meios previstos no Estatuto, a saber: recomendações, avisos, decisões, e até regulamentos ${ }^{20}$. E, além disso, no campo de aplicabilidade do art. 101, desde o $1{ }^{\circ}$ de janeiro de 1962, reina o princípio da maioria (qualificada) : o Conselho toma as ditas resoluções com 12 (ou mais) dos 17 votos, o que sublinha a supranacionalidade do processo de adaptação de direito.

$\mathrm{O}$ art. 102, finalmente, trata do caso em que um Estado membro intente modificar a sua legislação de modo a causar deformação do Mercado Comum. Compete à Comissão tomar as providências idôneas para evitar tal conseqüência contrária aos fins da CEE.

Verificamos, neste breve exame do Estatuto de Roma, que, com êle, existe a possibilidade de adaptar ou aproximar as leis dos Estados membros, inclusive as leis civis,

19. Vide WohlFarth, Direito Europeu, p. 21, 29 s., 32: legislação pelo Conselho, apesar do "caráter contratual" das suas resoluções. JAENICKE, também, afirma, no resultado, o caráter supranacional da CEE.

20. A diretriz, como o regulamento e a decisão, liga, sem porém, ao invés dêstes dois, ter fôrça legisladora direta. Ela só obriga aos Estados membros a editar prescrições (particulares) conformes, definindo a finalidade da modificação legislativa, mas deixando a sua realização aos Estados, vide o art. 189. 
por ato de autoridade supranacional, seja a adaptação ou aproximação sòmente recomendada aos Estados, seja ela ordenada - por diretriz, deixando a execução aos Estados (esta a maneira mais indicada); ou seja ela realizada diretamente - por via de regulamento, criando assim "ipso iure" direito supraestadual ${ }^{21}$.

Perguntando-nos qual o tipo de normas criadas ou a criar pela unificação do direito privado no seio da CEE, voltamos ao objeto geral do nosso ensaio.

Os regulamentos do Conselho dos Ministros, quando tiverem esta finalidade, instituirão normas materiais (supranacionais), eventualmente regras de processo civil (i.e. de competência), raras vêzes normas de conflito ${ }^{22}$. As diretrizes (meio primário da adaptação do direito), sendo ordens aos Estados membros para modificarem as disposições estatais divergentes, também não contêm, em geral, normas de conflito. Caso contiverem normas materiais será sòmente no sentido de padrão, conforme a "ratio legis" da modificação ordenada.

Temos ainda que definir a noção já tantas vêzes usada da "adaptação" ou "aproximação" ("rapprochement", "Angleichung") do direito, quer dizer destacá-la da "unificação" ou "uniformização", expressões habituais no direito internacional. Exprime-se nisso que a CEE não julga necessária a igualdade das normas estatais, a identidade das leis nacionais, mas só, em virtude da sua finalidade econômica, a concordância das regulamentações no efeito. Por isso, usa-se a noção de adaptação, aproximação das

21. Fica previsto e prescrito, além disso, no Estatuto da CEE, art. 220, a unificação das leis em distintas matérias mediante convenções entre os Estados membros, i.e. no plano da simples internacionalidade.

22. Lembre-se de que, no caso do Mercado Comum, a matéria é econômica e "nacionalmente indiferente", sendo por isso em primeiro lugar campo de aplicação da unificação direta, material; vide nota 8 e, p.ex., o Primeiro Regulamento de Execução relativo aos art. 85 e 86 sôbre cartéis. decretado pelo Conselho em 30-12-1961. 
normas particulares. No mesmo sentido o art. 56, cifra 2, por exemplo, fala da "coordenação" das legislações dos Estados membros sôbre a condição dos estrangeiros, o art. 99 da "harmonização" das leis do impôsto, o art. 54, cifra 3 letra c, simplesmente da eliminação de procedimentos e práticas administrativos contrários à liberdade de trânsito e permanência. Coordenação e harmonização indicam a tarefa, adaptação ou aproximação o meio a aplicar.

É possível o Conselho dos Ministros recomendar aos Estados membros a promulgação de leis nacionais idênticas, o que - se fizerem - será louvável; normalmente, porém, tal uniformidade é considerada dispensável - renúncia sábia em consideração das divergências existentes e das dificuldades da unificação do direito ${ }^{23}$. Aproximação ou adaptação, não unificação do direito, é o resumo da CEE para o nosso tema.

As normas adaptadas ou aproximadas são capazes de continuar a divergir quanto ao seu teor e até seu objeto, sendo possível que o mesmo alvo possa ser alcançado por vias legislativas bastante diferentes. Todavia, tal estado das coisas, ainda que satisfizesse a grosso modo as finalidades da CEE, não corresponderia ao postulado de legislações conformes; êste lema, além de ser condicionado pelas exigências econômicas, contém um momento jurídico, a saber: o momento em que os Estados membros integralizem o Mercado Comum com meios homogêneos. As normas nacionais a serem adaptadas ou aproximadas, de-

23. Isto menos em relação aos Estados fundadores da CEE: em cinco dêles (França, Itália, Bélgica, Países-Baixos, Luxemburgo) assim como em partes da Alemanha, está ou estava em vigor, numa ou noutra forma, o Código civil de Napoleão - também, até 1946, na Grécia, associada à CEE. Na Bélgica foi até promulgado novamente, em língua holandesa, em 30-12-1961. Fundamento de muitas ordens jurídicas européias era o direito romano que vigorava na Alemanha até o ano 1900, como "direito comum". - A entrada da Grã-Bretanha no Mercado Comum, porém, suscitaria problemas jurídicos, visto que o sistema continental de direito confrontar-se-ia com o "case law" anglo-americano. 
veriam, ao menos, fazer parte de instituições similares, sendo que, de outra forma, provocar-se-iam conflitos de qualificação e de competência.

Mesmo assim, com a interpretação "jurídica" de adaptação ou aproximação de direito, surgirão na prática colisões de leis que só desaparecerãó com textos uniformes. A menor divergência pode necessitar da aplicação de normas de conflito, e apenas a plena unificação do direito dispensará do D.I.P. ${ }^{24}$.

Para evitar divergências, do melhor modo posșível, o art. 177 do Tratado de Roma obriga os tribunais nacionais de última instância a submeter ao Tribunal da Comunidade, as questões de interpretação que se apresentarem em relação ao Estatuto, aos atos dos órgãos, etc. $O$ futuro dirá se êste procedimento de decisões prévias basta para manter a "conformidade" do direito ${ }^{25}$, e se esta satisfaz as exigências do Mercado Comum Europeu ou se, em seu lugar, é indispensável a unificação do direito, o Direito Uniforme ${ }^{26}$.

24. Vide Valladão, p. 121.

25. Rechtseinheitlichkeit, em lugar de Rechtseinheit, para citar os comentários oficiais alemães ao art. 177 e WALTER STRAUSS, Fragen der Rechtsangleichung im Rahmen der europaeischen Gemeinschaften (Questões da adaptação do direito nas Comunidades européias), Frankfurt/Main, 1959, p. 18/19.

26. RENÉ DAVID, Die Zukunft der europaeischen Rechtsordnungen: Vereinheitlichung oder Harmonisierung? (O futuro das ordens jurídicas européias: Unificação ou harmonização?), em ZWEIGERT, Colaboração européia no campo do direito, (citado na nota 8), p. 1, 10 s., prognostica, quanto à evolução do direito na Europa, uma consciência coletiva parecida ao "Common Law", seguida, num período posterior, da unidade do direito. 